\title{
Dekolonisasyon para sa Diwang Pilipino ni Emerita S. Quito: Isang Pagpupugay
}

\section{Rodrigo D. Abenes and Jerwin M. Mahaguay}

\begin{abstract}
This study is a tribute to the late great Filipino-philosopher Emerita S. Quito (11 September 1929 - 17 September 2017). This paper highlights her contention regarding the role of decolonization as a necessity for the restoration of Filipino identity. This paper is divided into three parts: the first part introduces Quito as one of the country's unique philosophers who aspired for the greater glory of the Filipino people; the second part features her thoughts on Filipino identity and decolonization as the ultimate symbol of her intellectual journey as a philosopher and patriot; and lastly, we shall try to show the weaknesses and limitations of Quito's views.
\end{abstract}

Keywords: Quito, Filipino identity, decolonization, tribute

\section{Panimula}

$\mathrm{N}$

ooong 17 Setyembre 2017, marami ang nalungkot sa pagkamatay ng bantog na pilosopong si Emerita S. Quito, ang itinuturing 'Socrates

ng Pilipinas.'1 Marami ang nagdalamhati, subalit sa kabila ng kalungkutang ito ay kapangahasan naming sinasambit na ang kanyang kamatayan ay hindi dapat maging pagluluksa, bagkus ito ay dapat maging isang pagdiriwang dahil sa kanyang iniwang pamana sa tradisyon ng pilosopiya sa Pilipinas. Siya ang nagsindi ng ilaw na hanggang ngayon ay nag-aalab at nagbibigay inspirasyon upang pag-ibayuhin at pagyamanin ang ugnayan ng pilosopiya at makabayang kaisipan at kamalayan. Kaya naman nais tahakin ng papel na ito na magbigay ng pagpupugay sa kanyang hindi matatawarang legasiyang nagbigay daan upang ang mga bagong sibol na

${ }^{1}$ Romualdo E. Abulad, Introduction to Emerita S. Quito, A Life of Philosophy: Festschrift in Honor of Emerita S. Quito (Manila: De La Salle University Press, 1990).

(C) 2017 Rodrigo D. Abenes and Jerwin M. Mahaguay https://www.kritike.org/journal/issue 21/abenes\&mahaguay december2017.pdf ISSN 1908-7330 


\section{DEKOLONISASYON AT DIWANG PILIPINO}

makabayang palaisip ay magpatuloy na sumalang sa paghahanap ng lalong kaluwalhatian ng lahing Pilipino sa pilosopikal na pamamaraan. ${ }^{2}$

Upang makamit ang nilalayon, binalangkas namin ang papel na ito sa tatlong bahagi: 1) ang pagpapakilala kay Emerita S. Quito bilang isang dakilang pantas sa kasaysayan ng pilosopiya sa Pilipinas; 2) ang pagpapakita ng kaisipan ni Quito ukol sa diwang Pilipino bilang tugatog ng kanyang intelektuwal na paglalakbay bilang isang pilosopo at bilang isang makabayan; 3) at ang huli ay ang pagbatikos sa kanyang pananaw sa diwang Pilipino, hindi upang igupo ang kanyang pananaw, kundi upang ipakitang binuksan niya ang panibagong diskurso sa pamimilosopiya sa Pilipinas na dapat tahakin ng mga bagong sumisibol na mga makabayang pilosopong Pilipino.

Ang pakikibahaging ito sa diskurso ng kamalayang-bayan ay masasabing sumisibol sa sinisimulang naratibo at sanaysay. Subalit buo ang aming paniniwala na ito ay isang likas na bahagi ng diyalekto para sa pagpapalutang ng higit na makabubuting pamantayan.

\section{Emerita Quito: Pangkaisipang Talambuhay}

Ang lahat ng dakilang adhikain ay nagsisimula sa pagkilala sa sarili, bilang tao, pamilya, pamayanan, at higit sa lahat, bilang isang nasyon. Ang lalim ng kamalayang-bayan ang huhusga sa tayog na maaabot ng isang nasyon. Kaya nga tungkulin ng mga intelektuwal na magnilay sa katahimikan ng gabi kung papaano kikilalanin ang hugis ng kamalayang ito at kung wala, ay bigyan ito ng hugis batay sa ninais na kahahantungan ng isang nasyon.

Si Emerita S. Quito ay isang pilosopo, intelektuwal, manunulat, edukador, at higit sa lahat ay makabayan. Noong 11 Setyembre 1929, isinilang siya sa isang gitnang-uring pamilya sa bayan ng San Fernando, Pampanga. ${ }^{3}$ Bagama't isinilang na babae sa pamilya, ang kanyang pamilya ay mayroon pantay na pagturing sa pagbibigay ng edukasyon na hindi limitado sa kasarian kaya naging madali sa kanya ang pagtahak sa landas ng pagkatuto. Dahil sa hangaring mag-aral ng abogasiya, nag-aral siya ng kursong pilosopiya sa Pamantasan ng Santo Tomas sa Maynila. Matapos ang ilang

\footnotetext{
${ }^{2}$ Ang papel na ito ay sagot din sa hamong nabanggit ni Emmanuel de Leon. Ayon sa kanya, "Napapanahon na upang basahin, dalumatin at kung kinakailangan ay batikusin ang mga akda ni Quito, malaki ang magagawa nito sa lalong pag-papaunlad ng pamimilosopiya sa ating bansa." See Emmanuel C. de Leon, "Emerita S. Quito (1929-): Ang Ugat ng Isang Panibagong Direksiyon ng Pamimilosopiya sa Pilipinas," in Malay 29:2 (2017): 30-46.

${ }^{3}$ Isa itong panahon kung saan ang damdaming pangkamakabayan ay umaalimpuyo dahil sa pagkakalaya mula sa mga Kastila at muling pagkakasadlak sa kamay ng bagong mananakop at manglulupig-ang mga Amerikano. Sa larangnan ng edukasyon ay napakasalimuot din ng panahon na ito lalo na sa pag-aaral ng mga kababaihan.
}

(c) 2017 Rodrigo D. Abenes and Jerwin M. Mahaguay https://www.kritike.org/journal/issue 21/abenes\&mahaguay december2017.pdf ISSN 1908-7330 
taong pag-aaral, tuluyan nang tumubog si Quito sa pilosopiya. Dahil dito agad din niyang ipinagpatuloy ang pag-aaral sa pamamagitan ng pagkuha ng Masterado sa Pilosopiya sa nasabing Pamantasan. Mula dito'y kanya nang kinalimutan ang pangarap na maging abogado. Ang kanyang pag-aaral sa Pamantasan ng Santo Tomas ay tuwirang mababanaagan sa kanyang kahusayan sa pilosopiyang Tomistiko. Ito ay makikita sa kanyang masteradong tesis na pinamagatang "The Will and Its Relation to the Divine Causality and Knowledge" noong 1956. Palibhasa'y likas ang kagalingan, sa kanyang pagtatapos ay kinuha siya ng nasabing Pamantasan upang magturo. Subalit ito ay naudlot nang tumulak siya sa Europa upang magpakadalubhasa at mag-aral ng Doktorado sa Pilosopiya sa Pamantasan ng Fribourg. Natapos niya ang kanyang disertasyon noong 1965 na pinamagatang "The Idea of Participated Liberty in the Philosophy of Louis Lavelle." Sa nabanggit na disertasyon, kanyang tinahak ang panibagong pamimilosopiya sapagkat ito ay hindi naaayon sa kanyang Tomistikong tradisyong natutunan. Sa kanyang pagbabalik, dinala niya ang makabagong uri ng pilosopiya sa iba't ibang pamantasan sa bansa gaya ng Pamantasan ng Santo Tomas, Pamantasang Ateneo De Manila, at Colegio ng Assumption, at Pamantasang De La Salle kung saan na siya nagturo hanggang sa kanyang pagreretiro. Masasabing ang kanyang ginawa sa panahong iyon ay mabigat, sapagkat ang nangingibabaw pa rin ang Tomistikong pananaw at ang pilosopiya ni Santo Tomas de Aquino. ${ }^{4}$ Dagdag pa niya:

The Thomist school, which is the most populous, stays close to the philosophy of Aristotle and Thomas Aquinas, and views all other philosophies in the light of Aristotelico-Thomism. This school considers as gospel truth the writings of the Catholic Saint. Hence, there is no originality in this school; no new ideas are forged; Catholic ideas of the Medieval Ages are repeated with more or less depth. The followers of this school still considers philosophy as ancilla theologiae (handmaid of theology), and therefore, philosophy should subserve theology

\footnotetext{
${ }^{4}$ Ang ganitong hinuha ay naayon din sa nagging pag-aaral ni Demeterio. See F.P.A. Demeterio, III, "Thomism and Filipino Philosophy in the Novels of Rizal: Rethinking the Trajectory of Filipino Thomism," in Academia, < $\underline{\text { https://www.academia.edu/7340247 }}$ /Thomism_and_Filipino_Philosophy_in_the_Novels_of_Jose_Rizal_Rethinking_the_Trajectory of Filipino Thomism>.

${ }^{5}$ Emerita S. Quito, The State of Philosophy in the Philippines (Manila: De La Salle University Press, 1983).
} 


\section{DEKOLONISASYON AT DIWANG PILIPINO}

Ang kanyang intelektuwal na buhay ay maaaring sabihing isang obra. Kung kaya nama'y hindi nag-atubili si Romualdo Abulad na bansagang "Socrates ng Pilipinas" si Emerita Quito. ${ }^{6}$ Buhat sa kanyang mga panayam, artikulo, komentaryo, at mga aklat ay mababanaag na isa siya sa sinasabi ni Florentino Timbreza na tagahawan ng pilosopiyang Pilipino. Bagama't malinaw na dalubhasa siya sa mga kaisipang Kanluranin at Silanganin, lagi niyang itinataas ang kaisipang Pilipino bilang isang kapantay na uri ng lahat ng tradisyon sa mundo. Buhay na buhay ang pagkamakabayan sa kanyang mga sulatin na makikita sa pagtatampok niya sa diwang Pilipino at dekolonisasyon.

Upang mas maunawan natin ang kaisipan ni Quito, mas mainam, marahil, na muling dalawin ang kanyang mga akda. Sa ibaba ay makikita ang talahanayan ng kanyang mga akda upang maging gabay sa mga mambabasa kung anu-ano ang pamimilosopiyang pinagkaabalahan ni Quito.

\begin{tabular}{|c|c|c|}
\hline Mga Taon & Pamagat ng Akda & Anyo \\
\hline \multirow[t]{11}{*}{$1956-1970$} & $\begin{array}{l}\text { 1956. "The Will and Its Relation with Divine Causality } \\
\text { and Knowledge." Unitas } 19\end{array}$ & Artikulo \\
\hline & $\begin{array}{l}\text { 1962. “On Jean-Paul Sartre and Louis Lavelle." Journal } \\
\text { of Education } 5 .\end{array}$ & Artikulo \\
\hline & $\begin{array}{l}\text { 1962. "The Integration of Religion in the Teaching of } \\
\text { Languages." Journal of Education } 4 .\end{array}$ & Artikulo \\
\hline & $\begin{array}{l}\text { 1966. “The 'Symposium' of Plato,” Philippiniana Sacra } \\
\text { 1:3. }\end{array}$ & Artikulo \\
\hline & $\begin{array}{l}\text { 1967. Address on a New Concept of Philosophy. Manila: } \\
\text { UST Press. }\end{array}$ & Aklat \\
\hline & $\begin{array}{l}\text { 1967. “Principles of Existentialism” [retitled: } \\
\text { "Existential Principles and Christian Morality." } \\
\text { Philippiniana Sacra } 2 .\end{array}$ & Artikulo \\
\hline & $\begin{array}{l}\text { 1967. “The Phenomenology of Edmund Husserl.” } \\
\text { Unitas } 40 .\end{array}$ & Artikulo \\
\hline & 1967. “The Meaning of Existentialism.” Unitas 40. & Artikulo \\
\hline & $\begin{array}{l}\text { 1967. "Existential Principles and Christian Morality." } \\
\text { Philippiniana Sacra 2:5. }\end{array}$ & Artikulo \\
\hline & $\begin{array}{l}\text { 1968. “The Theme of Absurdity in Albert Camus." } \\
\text { DLSC Dialogue } 4\end{array}$ & Artikulo \\
\hline & $\begin{array}{l}\text { 1969. La notion de la liberté participée dans la philosophie } \\
\text { de Louis Lavelle. Fribourg, Suisse: Studia Friburgensia, } \\
\text { Impreimerie St. Paul. }\end{array}$ & Aklat \\
\hline
\end{tabular}

${ }^{6}$ Abulad, Introduction to Quito, A Life of Philosophy.

(c) 2017 Rodrigo D. Abenes and Jerwin M. Mahaguay https://www.kritike.org/journal/issue 21/abenes\&mahaguay december2017.pdf ISSN 1908-7330

(cc) EY-NC-ND 


\begin{tabular}{|c|c|c|}
\hline & $\begin{array}{l}\text { 1969. “Existentialism and Phenomenology: An } \\
\text { Introduction.” DLSC Dialogue } 5 .\end{array}$ & Artikulo \\
\hline & $\begin{array}{l}\text { 1970. Herbert Marcuse and Contemporary Society. } \\
\text { Manila: University of Santo Tomas Press. }\end{array}$ & Aklat \\
\hline & $\begin{array}{l}\text { 1970. "Marcuse: Students Make the Best } \\
\text { Demonstrators." Manila Chronicle (13 February). }\end{array}$ & Artikulo \\
\hline & $\begin{array}{l}\text { 1970. "Should Communism Be Taught in the } \\
\text { Universities?" Horizons (April). }\end{array}$ & Artikulo \\
\hline \multirow[t]{21}{*}{ 1971-1982 } & $\begin{array}{l}\text { 1971. "Structuralism: A General Introduction." Unitas } \\
44: 1\end{array}$ & Artikulo \\
\hline & 1971. "Reflections on the Death of God." Unitas 44:2. & Artikulo \\
\hline & 1971. “On Structuralism.” Manila Chronicle (March). & Artikulo \\
\hline & $\begin{array}{l}\text { 1971. “Structuralism, Pilipino and a Universal } \\
\text { Language.” Manila Chronicle (17 March). }\end{array}$ & Artikulo \\
\hline & $\begin{array}{l}\text { 1971. “Philosophy in Pilipino, Anyone?” Manila } \\
\text { Chronicle (4 April). }\end{array}$ & Artikulo \\
\hline & $\begin{array}{l}\text { 1971. "Structuralism and Myth." Manila Chronicle (4 } \\
\text { April). }\end{array}$ & Artikulo \\
\hline & 1971. "Philosophy of Life." Manila Chronicle (2 May). & Artikulo \\
\hline & 1971. “The Oriental Mind.” Manila Chronicle (9 May). & Artikulo \\
\hline & $\begin{array}{l}\text { 1971. “Chance or Necessity.” Manila Chronicle (19 } \\
\text { May). }\end{array}$ & Artikulo \\
\hline & 1971. “The Filipino Mind.” Manila Chronicle (25 May). & Artikulo \\
\hline & 1971. “The Greek Mind.” Manila Chronicle (31 May). & Artikulo \\
\hline & 1971. “The Medieval Mind.” Manila Chronicle (7 June). & Artikulo \\
\hline & $\begin{array}{l}\text { 1971. “The Renaissance Mind.” Manila Chronicle (14 } \\
\text { June). }\end{array}$ & Artikulo \\
\hline & 1971. “The Modern Mind.” Manila Chronicle (20 June). & Artikulo \\
\hline & $\begin{array}{l}\text { 1971. “The Contemporary Mind.” Manila Chronicle (28 } \\
\text { June). }\end{array}$ & Artikulo \\
\hline & $\begin{array}{l}\text { 1971. “Contemporary Trends in Philosophy.” DLSC } \\
\text { Dialogue } 7 .\end{array}$ & Artikulo \\
\hline & $\begin{array}{l}\text { 1971. “Robert Andrey: Scientist or Philosopher?" } \\
\text { Unitas } 44 .\end{array}$ & Artikulo \\
\hline & $\begin{array}{l}\text { 1971-72. “The Philosophy of the Renaissance: An } \\
\text { Introduction." Sophia } 1 .\end{array}$ & Artikulo \\
\hline & $\begin{array}{l}\text { 1971-72. "The Philosophy of the Renaissance: Nicolas } \\
\text { of Cusa." Sophia } 1 .\end{array}$ & Artikulo \\
\hline & $\begin{array}{l}\text { 1971-72. "The Historical Concept of Being and Truth." } \\
\text { Sophia 1. [With an Open Forum]. }\end{array}$ & Artikulo \\
\hline & $\begin{array}{l}\text { 1971-72. "Open Forum on 'The Historical Concept of } \\
\text { Being and Truth.'” Sophia } 1 .\end{array}$ & Artikulo \\
\hline
\end{tabular}




\begin{tabular}{|c|c|}
\hline $\begin{array}{l}\text { 1972. Ang Pilosopiya sa Diwang Pilipino. Manila: United } \\
\text { Publishing Co. }\end{array}$ & Aklat \\
\hline $\begin{array}{l}\text { 1972. "The Evolving Concept of the University." } \\
\text { Faculty Forum. }\end{array}$ & Artikulo \\
\hline $\begin{array}{l}\text { 1973. "The Paradox of Freedom in Louis Lavelle." } \\
\text { Unitas } 46 .\end{array}$ & Artikulo \\
\hline 1973-74. “Ex Oriente Lux.” Sophia 3. & Artikulo \\
\hline 1974. "What Philosophy Ought to Be." Sophia 4. & Artikulo \\
\hline $\begin{array}{l}\text { 1974. Ang Kasaysayan ng Pilosopiya. Manila: Zone } \\
\text { Publishing Co }\end{array}$ & Aklat \\
\hline $\begin{array}{l}\text { 1974. "Regeneration of Moral and Social Values." } \\
\text { Beacon } 44\end{array}$ & Artikulo \\
\hline $\begin{array}{l}\text { 1975. Oriental Roots of Occidental Philosophy. Kuala } \\
\text { Lumpur: University of Malaya Press. Also published } \\
\text { (1975) by DLSU as Occasional Paper No. } 1 .\end{array}$ & Aklat \\
\hline $\begin{array}{l}\text { 1975. "A Short Introduction to Oriental Philosophy." } \\
\text { Sophia } 4 .\end{array}$ & Artikulo \\
\hline $\begin{array}{l}\text { 1975. “Pagsusuri: Ang Kasaysayan ng Pilosopiya." } \\
\text { DLSC Dialogue } 10 .\end{array}$ & Artikulo \\
\hline $\begin{array}{l}\text { 1977. “Philosophy of History: An Introduction." } \\
\text { DLSU Dialogue } 13 .\end{array}$ & Artikulo \\
\hline 1977. "Reflections on the Death of God.” Unitas 50. & Artikulo \\
\hline $\begin{array}{l}\text { 1978. "The Role of the University in Changing } \\
\text { Women's Consciousness." DLSU Dialogue } 14 .\end{array}$ & Artikulo \\
\hline $\begin{array}{l}\text { 1978-79. “How Original is Hegel's ‘Philosophy of } \\
\text { History'?” Unitas 51. Also published in Sophia } 8 \text { (1978- } \\
\text { 79). }\end{array}$ & Artikulo \\
\hline $\begin{array}{l}\text { 1979. “Ang Kayamanan ng Ating Wika [Retitled: } \\
\text { “Ang Kayamanan ng Wikang Filipino"]." Daop Diwa } \\
\text { 3. }\end{array}$ & Artikulo \\
\hline $\begin{array}{l}\text { 1979. Lectures on Comparative Philosophy. Occasional } \\
\text { Paper No. 7. Manila: De la Salle University. }\end{array}$ & Aklat \\
\hline $\begin{array}{l}\text { 1979. Four Essays in the Philosophy of History. Manila: } \\
\text { DLSU Office of Research }\end{array}$ & Aklat \\
\hline $\begin{array}{l}\text { 1979. “University's Role in Changing Women's } \\
\text { Consciousness." In Role of the University in Women's } \\
\text { Movement. Edited by Iva I. Shipstone and Nora } \\
\text { Shipstone. Lucknow, India: The Asian Women's } \\
\text { Institute. }\end{array}$ & Artikulo \\
\hline $\begin{array}{l}\text { 1979. Ang Pilosopiya ng Tao. Manila: Phoenix } \\
\text { Publishing Co. }\end{array}$ & $\begin{array}{c}\text { Aklat } \\
\text { (katuwang na } \\
\text { manunulat) }\end{array}$ \\
\hline
\end{tabular}




\begin{tabular}{|c|c|c|}
\hline & $\begin{array}{l}\text { 1980. "Process Philosophy: An Introduction." Sophia } \\
\text { 9. }\end{array}$ & Artikulo \\
\hline & $\begin{array}{l}\text { 1980-81. “Ang Pilosopiya: Batayan ng Pambansang } \\
\text { Kultura," Daop Diwa } 6 .\end{array}$ & Artikulo \\
\hline & $\begin{array}{l}\text { 1981. Homage to Jean-Paul Sartre. Manila: De La Salle } \\
\text { University }\end{array}$ & Aklat \\
\hline & $\begin{array}{l}\text { 1981. "The Philosophy of Avicenna in the Twentieth } \\
\text { Century." Sophia } 11 .\end{array}$ & Artikulo \\
\hline & $\begin{array}{l}\text { 1982. "An Existentialist Approach to Ecumenism." } \\
\text { Sophia } 12\end{array}$ & Artikulo \\
\hline \multirow[t]{12}{*}{ 1982-1986 } & $\begin{array}{l}\text { 1983. The State of Philosophy in the Philippines. Manila: } \\
\text { De la Salle University Research Center. }\end{array}$ & Aklat \\
\hline & $\begin{array}{l}\text { 1983. “Ang Sariling Wika, Ang Pilosopiya, at ang mga } \\
\text { Tao.” In Mga Babasahin sa Pilosopiya: Epistemolohiya, } \\
\text { Lohika, Wika at Pilosopiyang Pilipino. Compiled by } \\
\text { Virgilio G. Enriquez. Quezon City: Surian ng } \\
\text { Sikolohiyang Pilipino. }\end{array}$ & Artikulo \\
\hline & 1983. “A Filipino Philosophy of Value." Sophia 13. & Artikulo \\
\hline & $\begin{array}{l}\text { 1983. "Structuralism and the Filipino Volksgeist." } \\
\text { DLSU Dialogue } 18 .\end{array}$ & Artikulo \\
\hline & $\begin{array}{l}\text { 1984. “A Filipino Volgeist in Vernacular Literature." } \\
\text { Karunungan } 1 .\end{array}$ & Artikulo \\
\hline & 1984. “Isang Teorya ng Pagpapahalaga." Malay 3:2. & Artikulo \\
\hline & $\begin{array}{l}\text { 1984. “A Philosophy of Education for Filipinos." Alab } \\
\text { 1. Also in PESP Yearbook No. } 5 \text { (1984). }\end{array}$ & Artikulo \\
\hline & $\begin{array}{l}\text { 1984. "Values as a Factor in Social Action." } \\
\text { International Social Science Journal } 36 .\end{array}$ & Artikulo \\
\hline & $\begin{array}{l}\text { 1985. “Pilosopiya ng Edukasyon sa Diwang Pilipino." } \\
\text { Malay } 4 .\end{array}$ & Artikulo \\
\hline & $\begin{array}{l}\text { 1985. "Philosophical Conception of Value." Sangguni } \\
\text { 8. }\end{array}$ & Artikulo \\
\hline & $\begin{array}{l}\text { 1985. "A Morality of Ambiguity or the Ambiguity of } \\
\text { Morality." Sophia } 15 .\end{array}$ & Artikulo \\
\hline & $\begin{array}{l}\text { With Romualdo Abulad, Herminia Reyes, and } \\
\text { Florentino Timbreza. 1985-86. “Ulat Tungkol sa } \\
\text { Sanggunian at Leksikon ng Pilosopiya.” Malay } 5 .\end{array}$ & Artikulo \\
\hline \multirow[t]{3}{*}{ 1986-1992 } & $\begin{array}{l}\text { 1986. Three Women Philosophers. Manila: De La Salle } \\
\text { University Press. }\end{array}$ & Aklat \\
\hline & $\begin{array}{l}\text { 1986. “Maaari Bang Magtagumpay ang Komunismo } \\
\text { sa Pilipinas?” Malay } 5 .\end{array}$ & Artikulo \\
\hline & $\begin{array}{l}\text { 1986. "Pulong-isip: Meeting of Filipino Minds." } \\
\text { Karunungan 3; Sophia } 15 .\end{array}$ & Artikulo \\
\hline
\end{tabular}




\section{DEKOLONISASYON AT DIWANG PILIPINO}

\begin{tabular}{|c|c|c|}
\hline & $\begin{array}{l}\text { 1987. “Ang Kaugnayan ng Wikang Pambansa at } \\
\text { Edukasyon.” Malay } 6 .\end{array}$ & Artikulo \\
\hline & $\begin{array}{l}\text { 1988. "Louis Lavelle's Concept of Freedom." Sophia } \\
\text { 18. }\end{array}$ & Artikulo \\
\hline & $\begin{array}{l}\text { 1988. "The Ambivalence of Filipino Traits and } \\
\text { Values." Karunungan } 5 .\end{array}$ & Artikulo \\
\hline & $\begin{array}{l}\text { 1989. “Ang Pilosopiya ng Tao." In Readings in the } \\
\text { Philosophy of Man. DLSU Philosophy Department: De } \\
\text { La Salle University. }\end{array}$ & Artikulo \\
\hline & $\begin{array}{l}\text { 1988. “Jacques Derrida: A Demystification.” DLSU } \\
\text { Graduate Journal } 14 .\end{array}$ & Artikulo \\
\hline & 1989. Fundamentals of Ethics. Manila: DLSU Press. & Aklat \\
\hline & $\begin{array}{l}\text { 1989. "A Structural Approach to Philippine Epics } \\
\text { [focus on the Ulahingan and Biag ni Lam ang]." } \\
\text { Published by the Cultural Center of the Philippines. }\end{array}$ & Artikulo \\
\hline & $\begin{array}{l}\text { 1989. “Isang Teorya ng Pagpapahalaga." In Readings } \\
\text { in the Philosophy of Man. DLSU Philosophy } \\
\text { Department: De La Salle University Press. }\end{array}$ & Artikulo \\
\hline & $\begin{array}{l}\text { 1989. “Ang Konsepto ng Kalayaan ni Louis Lavelle.” } \\
\text { Karunungan 6; also in Sofia } 18 \text { (1988). }\end{array}$ & Artikulo \\
\hline & $\begin{array}{l}\text { 1989. “The Relevance of the National Language to } \\
\text { Education." DLSU Graduate Journal } 14 .\end{array}$ & \\
\hline & $\begin{array}{l}\text { 1990. A Life of Philosophy: Festschrift in honor of Emerita } \\
\text { S. Quito. Manila: De la Salle University Press. [A Life } \\
\text { of Philosophy, Selected Works (1965-1988). Manila: } \\
\text { De la Salle University Press.] }\end{array}$ & Aklat \\
\hline & $\begin{array}{l}\text { 1990. “Teaching and Research of philosophy in the } \\
\text { Philippines.” In A Life of Philosophy. Manila: De la } \\
\text { Salle University Press. }\end{array}$ & Artikulo \\
\hline & $\begin{array}{l}\text { 1990. “Homage to Jean-Paul Sartre.” In Readings in } \\
\text { Filipino Philosophy. DLSU Philosophy Department: De } \\
\text { la Salle University Press. }\end{array}$ & Artikulo \\
\hline & $\begin{array}{l}\text { 1990. “The Hermeneutics of Jurgen Habermas.” } \\
\text { Sophia } 20 .\end{array}$ & Artikulo \\
\hline & $\begin{array}{l}\text { 1991. The Merging Philosophy of East and West. Manila: } \\
\text { DLSU Press. }\end{array}$ & Aklat \\
\hline & $\begin{array}{l}\text { 1992. “St. John Baptist de La Salle's Philosophy of } \\
\text { Education in the Philippine Context." In St. John } \\
\text { Baptist de La Salle and Education Today. Manila: De La } \\
\text { Salle University Press. }\end{array}$ & Artikulo \\
\hline $1993-1997$ & $\begin{array}{l}\text { 1993. “Teaching as an Art.” DLSU Newsletter (8 } \\
\text { February). }\end{array}$ & Artikulo \\
\hline
\end{tabular}




\begin{tabular}{|c|c|c|}
\hline & $\begin{array}{l}\text { 1993. Ensayklopidiya ng Pilosopiya. Manila: De La Salle } \\
\text { University Press. }\end{array}$ & $\begin{array}{c}\text { Aklat } \\
\text { (katuwang na } \\
\text { manunulat) }\end{array}$ \\
\hline & $\begin{array}{l}\text { 1994. "Philosophy of Education for Filipinos." In } \\
\text { Philosophy of Education: Concerns, Purposes, Content, } \\
\text { and Methods of Education. Edited by Celeste O. Botor } \\
\text { and Aniceta M. Ortinero. Manila: Rex Book Store. }\end{array}$ & Artikulo \\
\hline & 1997. “A Concept of Hero.” Karunungan 10-14. & Artikulo \\
\hline & $\begin{array}{l}\text { 1999. "Frank Tipler's The Physics of Immortality." } \\
\text { Karunungan } 16 .\end{array}$ & Artikulo \\
\hline & 2000. "Introduction to Hermeneutics." Karunungan 17. & Artikulo \\
\hline $2000-2003$ & $\begin{array}{l}\text { 2000. "Pro Death Penalty: Hic et Nunc." Karunungan } \\
\text { 17. }\end{array}$ & Artikulo \\
\hline & $\begin{array}{l}\text { 2001. Phenomenology: Edmund Husserl and Edith Stein. } \\
\text { Manila: De La Salle University Press. }\end{array}$ & Aklat \\
\hline & $\begin{array}{l}\text { 2002. Critique of Historical Theory. Manila: De La Salle } \\
\text { University Press. }\end{array}$ & Aklat \\
\hline & 2002. "God in the Third Millennium." Karunungan 19. & Artikulo \\
\hline & $\begin{array}{l}\text { 2002. "Philosophy as a Critique of Society." } \\
\text { Karunungan } 19 .\end{array}$ & Artikulo \\
\hline & $\begin{array}{l}\text { 2003. "A New Concept of Philosophy." Karunungan } \\
\text { 20. }\end{array}$ & Artikulo \\
\hline
\end{tabular}

Talahanayan 1: Mga Akda ni Emerita S. Quito7

Walang isang sistema o paksang masasabing magtatahi sa mga iisinulat ni Quito. Hindi dahil wala siyang direksyon sa kanyang pag-iisip o pagsusulat, kundi dahil hindi siya maaaring ikahon sa isang panahon o paksa lamang. Buhay at gumagalaw ang pilosopiya para kay Quito kaya iisinulat niya ito sa anumang anyo kung paano ito magbigay ng inspirasyon sa kanya. Maaaring tawaging eklektiko ang kanyang pamamaraan subalit hindi iyon limitasyon bagkus, ito'y isang pagpapakita ng yaman at lawak ng kanyang abot-tanaw-isip. Gayunpaman, ikinakatuwiran ng papel na ito ang kanyang kaisipan ukol sa diwang Pilipino bilang pagpupugay sa kanyang pagiging pilosopong Pilipino, o mas mainam na sabihing makabayang pilosopo.

${ }^{7}$ Ang talahanayang ito ay modipikasyon sa talahanayang gawa ni De Leon. Minarapat lang naming pagsunud-sunurin ang mga akda, kahit may pagkakaiba ito sa anyo-aklat man o artikulo. See De Leon, "Apendiks 1: Mga Akda ni Emerita Quito, 1956-2003," in "Emerita S. Quito (1929-)," 43-46. 
Gayundin sa ginawang pag-aaral ni De Leon sa mga isinulat ni Quito, ${ }^{8}$ gamit ang mungkahing taksonomiya ng pilosopiyang Pilipino ni Demeterio, ${ }^{9}$ makikitang isang-katlo sa kabuuan ng mga akda ni Quito ay tungkol sa diwang Pilipino. $12.5 \%$ ang pananaliksik tungkol sa pananaw sa mundo ng mga Pilipino; $6.25 \%$ naman ang tungkol sa pananaliksik hinggil sa pagpapahalaga sa etikang Pilipino; at $15.62 \%$ naman ang pamimilosopiya tungkol paggamit ng wikang Filipino. Samakatuwid, masasabing ang tahakin naming magbigay ng pagpupugay ay makatarungan sapagkat isangkatlong bahagi ng kanyang isinulat ay patungkol sa pag-aaral sa diwang Pilipino.

Subalit bago tuluyang saysayin ang kanyang kaisipan ukol sa diwang Pilipino, nararapat lamang na magkaroon muna ng pagtatalas ukol sa katwiran kung bakit niya ito naisulat-mga dahilan at karanasang nagtulak sa kanya upang magtika sa paksang ito. Marapat ding ipakita ang kanyang pamamaraang ginamit sa pagbalangkas ng kanyang kaisipan bilang pundasyon ng kadalisayan ng kanyang hangarin at kaisipan.

Bagama't wala na si Quito para saysayin ang mga dahilan ng pagtataya niya sa diwang Pilipino, mayroon namang mga akda na siyang maaaring gawing pamantayan sa pagninilay dito. Una, kung babalikan ang kanyang mga akda ukol sa wikang Filipino, sinabi niya na dala ng kanyang karanasan sa pag-aaral sa Europa at ang kanyang pakikisalamuha sa iba't ibang pagtitipon sa pilosopiya, nakita niyang mas kinikilala ng mga dayuhan ang mga Asyano, o mga dayuhan na may pagtitika sa sariling wika at identidad bilang isang bansa. Samakatuwid, hindi kahanga-hangang magaling tayo sa wikang banyaga o kalinangang-banyaga, sapagkat ang kahanga-hanga ay ang pagtataguyod at pagpapaunlad sa sariling wika at kalinangan. Pangalawa, mapapansin na ang panahon kung kailan nagsimulang magtika si Quito sa diwang Pilipino ay nagsimula sa pagtatapos ng dekada '70 hanggang sa dekada '80. Ang panahong ito ay kritikal dahil panahon ito ng paghahanap sa pagkakakilanlan ng Pilipino sa iba't ibang larangan. Ang dating-pangulong Ferdinand E. Marcos ay naglayong magpasimula ng bagong kamalayang Pilipino sa pagtatatag niya ng Bagong Lipunan. Samantalang si Virgilio Enriquez naman ay nagpasimula ng kanyang Sikolohiyang Pilipino. Sa larangan ng Sosyolohiya at kasaysayan, itinulak naman ni Salazar ang Pantayong Pananaw. Samakatuwid, makikita sa panahong ito ang igting ng pagnanasa ng bawat isa na isulong ang isang makabayang pananaw sa iba't ibang larangan. Tunay ngang hindi natutulog ang pilosopo sa panahong iyon dahil kay Quito.

8 Ibid.

${ }_{9}$ F.P.A. Demeterio III, “Status and Directions for 'Filipino Philosophy' in Zialcita, Timbreza, Quito, Abulad, Mabaquiao, Gripaldo, and Co" in $\Phi$ ı $\mathrm{Co \sigma o \varphi}^{\prime} \alpha$ : International Journal of Philosophy 14:2 (2013).

(c) 2017 Rodrigo D. Abenes and Jerwin M. Mahaguay https://www.kritike.org/journal/issue 21/abenes\&mahaguay december2017.pdf ISSN 1908-7330

(c) BY-NC-ND 
Buo ang aming pananalig na ang pagtatampok ni Quito sa diwang Pilipino ay bunga ng kanyang pagnanais na maiangat ang kalagayan ng kanyang bayan at hindi bahagi lamang ng kanyang pakikipagtagisan sa mga pilosopo sa kanyang panahon. Makikita natin sa kanyang mga akda ang mga paksa patungkol sa pilosopiya ng edukasyon, pilosopiya sa Pilipinas, at kaisipang Pilipino. Bunga nito ang pagpapahiwatig na hindi na mahalaga sa kanya ang pamamaraan; ang mahalaga na lamang ay ang kanyang isinusulong na adhikain, kung kaya nga't maaaring sabihing eklektiko ang kanyang pamamaraan sa pagsusulong sa diwang Pilipino. Lumabas ito sa kanyang sulatin ukol sa mga kababaihan, edukasyon, pilosopiya, kasaysayan at lalong higit, ay sa hinaharap ng lahing Pilipino. Makatuwiran ding sabihin na maaaring binagtas niya ang kritikal na pamamaraan lalo na sa pagtingin niya sa mga dayuhan bilang tagapaghawak ng kapangyarihang umaalipin sa kamalayang katutubo. Sa huli, mas marami pa rin ang hindi nasabi tungkol kay Quito, sapagkat napakarami pang paraan at kwentong dapat saysayin para lubusan siyang ipakilala, subalit batay sa kanyang pamamaraan at pananaw ay walang ibang pinakamakatuwirang gawin para lubusan siyang makilala, kundi basahin, siyasatin, at batikusin ang kanyang mga akda at nagawa. ${ }^{10}$

\section{Ang Diwang Pilipino ayon kay Quito}

Malinaw kay Quito na hindi isang pisikal na katangian ang magbubuklod sa pagka-Pilipino. Ayon nga sa kanya, "kung ang hinahanap natin ay ang hugis ng katawan o kulay ng balat o tabas ng mata, ay walang kasarilinang Pilipino, datapwat mayroong kasariling diwa (soul identity) ang Pilipino at hango ito sa pilosopiyang taglay ng bayang Pilipino."11 "Volkgeist" sa wikang Aleman, "spirit of the people" naman sa wikang Ingles, at diwa sa wikang Filipino na siyang ginamit ni Quito para sa kamalayang ito. Para sa kanya, diwa ang sumasalamin sa pangkalahatang kamalayan ng mga Pilipino. Ang diwang ito naman, bilang kamalayan, ay maaaring tawaging pilosopiya. Ang diwang ito ay makikita sa mga mito at alamat na nagpapakita ng kanilang pagpapahalaga at gawi. Mahalaga ang mga ito, ayon kay Quito, sapagkat dito naipapahatid ang kanilang "deeper feeling."12 Ang ganitong pananaw sa batayan ng pagka-Pilipino bilang diwa ay paraang

\footnotetext{
${ }^{10}$ De Leon, “Emerita S. Quito (1929-)."

${ }^{11}$ Emerita S. Quito, "Ang Pilosopiya: Batayan ng Pambansang Kultura" in A Life of Philosophy: Festschrift in Honor of Emerita S. Quito (Manila: De La Salle University, 1990), 686.

${ }_{12}$ Emerita S. Quito, "A Filipino Volksgeist in Vernacular Literature" in A Life of Philosophy: Festschrift in Honor of Emerita S. Quito (Manila: De La Salle University, 1990), 754.

(C) 2017 Rodrigo D. Abenes and Jerwin M. Mahaguay https://www.kritike.org/journal/issue 21/abenes\&mahaguay december2017.pdf ISSN 1908-7330 
tinatahak din ni Virgilio Enriquez ${ }^{13}$ sa pag-aaral naman niya ng katangian ng sikolohiyang Pilipino.

Kung gayon, ang katangiang Pilipinong sinasabi ni Quito ay hindi limitado sa pisikal na kaanyuan. Ang ideya ni Quito ay higit na tumutukoy sa kolektibong kamalayan ng mga mamamayang Pilipino, sapagkat lampas ito sa panlabas na pamantayan lamang. Tinatahi ng kaisipan ni Quito ang pagkakaibang panlabas ng mga Pilipino sa buong bansa. ${ }^{14}$ Samantalang ayon pa nga kay Quito, ang diwang iyon ay naroroon na bago pa man dumating ang mga mananakop. Ito ay dalisay at "free from foreign influence, unsullied by foreign contact." 15 Ang ganitong kadalisayan ay makikita sa mga alamat at kwentong-bayan, sapagkat dito mababanaag ang pagtatalastasan ng kaisipan o diwa ng mga tao at ng kanilang pilosopiya. Ito ay makikita sa wika ni Quito na:

What is the function of myths and legends? For one thing, they are the gauge of a people's psyche; they constitute the collective consciousness of a people vis-àvis a deity or an event. Hence there must be a connection between myths and a people's indigenous thought or between and grassroots philosophy. ${ }^{16}$

Dagdag pa niya, mababakas ang mga panitikang ito sa mga panitikan at ugaliin sa mga lalawigan na naisulat sa mga wikang bernakular na wika "the Filipino soul can be better gleaned from the prism of vernacular literature since it reflects grassroots thinking and living." 17 Dito, makikita na malaki ang tiwala ni Quito sa mga naisulat sa lalawigan kaysa sa mga manunulat sa lungsod sapagkat mas nakaampat ito sa kadalisayan ng diwang-Pilipino. Isa sa ibinigay niyang halimbawa ay ang "Pampango vernacular literature"18 bilang isa sa mga batayan ng diwang Pilipino. ${ }^{19}$ Upang mas higit na maunawaan kung ano nga ba ang Diwang Pilpino, mas mainam na balangkasin natin ang mga sumunod na diskurso ni Quito tungkol sa: 1) Katangian ng Diwang

\footnotetext{
13 Virgilio Enriquez, From Colonial to Liberation Psychology: The Philippine Experience. (Manila, Philippines: De La Salle University Press, 1994).

${ }^{14}$ Jerwin M. Mahaguay, Ang Pilosopiya ng Edukasyon para sa mga Pilipino ayon kay Emerita S. Quito: Isang Pagsusuri (Ph.D. Dissertation, Manila, Philippines: De La Salle University, 2013).

${ }^{15}$ Emerita S. Quito, "Structuralism and the Filipino Volksgeist" in A Life of Philosophy: Festschrift in Honor of Emerita S. Quito (Manila: De La Salle University Press, 1990), 732.

${ }^{16}$ Ibid.

${ }^{17}$ Quito, “A Filipino Volksgeist in Vernacular Literature," 755.

18 Ibid., 755-760.

19 See Jerwin M. Mahaguay, “Nasyonalismo: Lakas ng Edukasyong Pilipino," in Kaisipan: Ang Opisyal na Dyornal ng Isabuhay, Saliksikin, Ibigin ang Pilosopiya (ISIP) 1:1 (2013): 2840.

(c) 2017 Rodrigo D. Abenes and Jerwin M. Mahaguay https://www.kritike.org/journal/issue 21/abenes\&mahaguay december2017.pdf ISSN 1908-7330

(c) BY-NC-ND
} 
Pilipino, 2) Diwang Pilipino sa Panahon ng Pananakop, at 3) Pagbalik sa Diwang Pilipino sa pamamagitan ng Dekolonisasyon.

\section{Katangian ng Diwang Pilipino}

Masalimuot ang pagtatalas ng mga talagang katangian na tiyak na maglalarawan sa diwang Pilipino lalo na at napakalawak at napakarami ng mga katutubo na dapat balikan bago dumating ang mga dayuhan upang ito ay tukuyin. Kaya naman, may mga ilan lamang binigyan ng pansin si Quito. Upang maging payak ang paglalarawan sa katangiang ito, hinati ang mga akda ni Quito sa dalawa: una, ang pagiging relihiyoso; at pangalawa, ang pagkakaroon ng kakaibang batayan ng gawi at pagpapahalaga sa buhay. ${ }^{20}$

Una, noon pa man ay may malalim nang paniniwala ang mga Pilipino sa isang Kataas-taasang Nilalang o "Supreme Being." Kinuha ni Quito ang pag-aaral ni Pablo Fernandez ${ }^{21}$ na nagsabing noon pa man ay mayroon nang kinikilalang Diyos ang mga Tagalog - si Bathala; Laon sa mga Visaya; at Cabunian sa mga Ilokano. Kaya naman, tulad ni Landa Jocano ${ }^{22}$ ay naniniwala si Quito na bago pa man dumating ang mga Kastila ay napakalaki na nang ginagampanan ng paniniwala sa Diyos o relihiyon sa bansa. Bagama't ang relihiyong ito ay hindi pormal o walang isang sistema. Ang relihiyong ding ito ay may sariling paraan ng pagpapaliwanag ng paglikha.

Ikalawa, mayroon ring sistemang pagpapahalaga ang mga Pilipino na nakabatay sa paniniwala sa Diyos o kay Bathala, at sa Batas ng Panunumbalik na may kahawig sa batas ng Karma ng mga Indiyano. ${ }^{23}$ Ang mga batayan ng pagpapahalaga at gawi na ito ay ang mga sumusunod:

Bahala na. Ito ay galing sa salitang Bathala na. Nangangahulugan ito pagbibigay ng tiwala sa Bathala sa lahat ng maaaring maganap sa isang gawain o adhikain sa buhay. Samakatwid ay nag-uugat ito sa matinding pananampalataya sa Kataas-taasang Bathala.

Gulong ng Palad. Paikot mag-isip ang mga Pilipino. Naniniwala sila na lahat ay nagbabago sa buhay. Lahat ay matatapos at mapapalitan, pagkatapos ng hirap ay saya naman at pagkatapos ng saya ay hirap kaya dapat itong paghandaan.

\footnotetext{
${ }^{20} \mathrm{Ibid}$.

${ }^{21}$ Pablo Fernandez, History of the Church in the Philippines (1521-1898) (Manila: National Book Store, 1979) as cited in Quito, "Structuralism and the Filipino Volkgeist," 733.

${ }^{22}$ As cited in Quito, "Struturalism and the Filipino Volkgeist," 733.

${ }^{23}$ Ibid.
}

(C) 2017 Rodrigo D. Abenes and Jerwin M. Mahaguay https://www.kritike.org/journal/issue 21/abenes\&mahaguay december2017.pdf ISSN 1908-7330 
Kagandahang-loob. Mapagbigay at maalaga ang mga Pilipino. Maayos silang tumanggap sa mga bisita at matulungin. Isang halimbawa nito ay makikita sa kanilang bayanihan.

Reciprocity. Ito ay ang pagkilala na ang mga bagay na tinatanggap buhat sa kapwa ay nararapat ding ibalik at bigyan ng karampatang pagpapahalaga. Makikita ito sa mga gawi tulad ng: paggalang sa matatanda, pakikisama, utang na loob (mas maipaliliwanag sa susunod na paksa).

Hiya. Ito ay maaaring tingnan sa iba't ibang aspeto tulad ng kawalan ng sariling kusa, kawalan ng kakayahang tumanggi sa kahilingan ng iba, at kawalan ng tiwala sa sarili. ${ }^{24}$

Ganap at isinasabuhay ng mga katutubo ang mga katangiang ito, subalit, ayon kay Quito, sa pagdating ng mga dayuhan, ang diwang ito na nakatago sa mga panitikan ay natabunan at napalitan. Nagbago ang sitwasyon kaya naligaw at nalunod ang mga Pilipino sa bagong kalinangan, bagong gawi, at bagong pagpapahalaga.

\section{Diwang Pilipino sa Panahon ng Pananakop}

Sa pagdating ng mga mananakop ay nawala ang kadalisayan ng Diwang Pilipino sapagkat ito ay nakakawing sa implikasyon ng kolonyalismo. Ito ay bunga ng pananakop ng mga dayuhan sa ating bansa sa loob halos ng 400 na taon-humigit-kumulang na tatlong daang taon sa mga Kastila, limampu sa mga Amerikano, at tatlong taon naman sa mga Hapon. Kaya naman masasabing ang mga Pilipino ay nagkaroon ng colonial mentality o pag-iisip kolonyal, ${ }^{25}$ kagawiang banyaga, at hilaw na pagpapahalaga.

\section{Pag-iisip na Banyaga}

Tuwirang sinasabi ni Quito na dahil sa sobrang tagal na karanasan ng mga Pilipino sa pananakop ng mga dayuhan, nagkaroon tayo ng 'inferiority complex.' Ibig sabihin nito ay "mas nadadaig ng kanilangan

${ }^{24}$ Ibid., 734-737.

${ }^{25}$ Emerita S. Quito, “Pilosopiya ng Edukasyon sa Diwang Filipino," in Malay 4 (1985),

1.

(c) 2017 Rodrigo D. Abenes and Jerwin M. Mahaguay https://www.kritike.org/journal/issue 21/abenes\&mahaguay december2017.pdf ISSN 1908-7330

\section{(c) $)$ BY-NC-ND}


kalinangan (dayuhan) ang likas na kalinangan (sinasakop)." ${ }^{26}$ Ang pag-iisipkolonyal ay resulta na rin ng pananakop ng mga dayuhan sa hindi lamang sa kalupaan kundi sa larangan ng kultura o kalinangan.

Ang ganitong kaisipan ay nagbunga ng talumbalikan: ang pagkagalit at pagkapoot sa mga dayuhan. Pagkapoot sa mga dayuhan dahil sa pagkalusaw ng kanilang mga kalinangan, gawi, at kultura. Ngunit, bagama't may pagkapoot, mayroon ding hindi mawaring paghanga sa kulturang kanluranin na animo'y mas mataas ang kanilang kultura kaysa sa atin. Kaya sa kabila ng poot ay makikita na patuloy pa ring ginagamit ang wika, gawi, pagpapahalaga, at relihiyon ng mga dayuhan upang sa gayon ay mapabilang sila sa kanilang hinahangaan. Kaya naman tahasang sinabi niya na "karaniwan sa mga bayang nasakop ay mahigpit pang kumakapit sa kuldon ng kongkistador." 27 Kung gayon, mismong mga nasakop o colonial subjects ang nagpupumilit na itago ang kanilang mga sarili sa anino ng mga mananakop. Mas pinipilit nilang ibilang ang kanilang mga sarili sa anyo ng mga dayuhan kaysa balikan ang kanilang sariling kalinangan.

Kaya masasabing hindi na puro at buo ang kalinangang Pilipino sapagkat ito ay hindi kalinangan-dalisay sapagkat "ang kalinangan ay sagisag ng isang bayan: ang kabuuan ng kanyang kasaysayan, wagas at walang bakas ng banyagang ideolohiya." ${ }^{28}$ Ang pag-iisip ng mga Pilipino ay may pagkaunyangong banyaga na nagiging sanhi ng pagkiling sa banyagang kalinangan at kabihasnan. Bagama't malinaw na may pagkiling sa kalinangang banyaga, ang masama pa rito, aniya, ay di malinaw kung saang kalinangan kumikiling, kung sa Silanganin o Kanluranin. Kaya naman, ayon kay Quito "Filipino can be said to be a cultural hermaphrodite who stays on the borderline between East, and West without knowing whether he belongs to one or to the other. ${ }^{\prime 29}$

\section{Gawing Banyaga}

Maaaring ilatag ang mga kagawiang nakita ni Quito sa apat na grupo: katamaran, pagkamakasarili, karuwagan, at kahinahunan. ${ }^{30}$ Ang saysay ng mga kagawiang ito, ayon kay Quito, ay mabuti o masama lamang depende kung saan at kaninong pananaw ang gagamitin. Kung sa

\footnotetext{
${ }^{26}$ Ibid., 2.

${ }^{27}$ Ibid.

${ }^{28}$ Ibid.

${ }^{29}$ Quito, “A Filipino Volksgeist in Vernacular Literature," 754.

${ }^{30}$ Mahaguay, Ang Pilosopiya ng Edukasyon para sa mga Pilipino ayon kay Emerita S. Quito:
} Isang Pagsusuri.

(C) 2017 Rodrigo D. Abenes and Jerwin M. Mahaguay https://www.kritike.org/journal/issue 21/abenes\&mahaguay december2017.pdf ISSN 1908-7330 
makasilangang kalinangan ang gagamitin, mabuti ang mga gawing ito; samantala, kung sa kanluran naman ay magiging kahinaan ang mga ito. ${ }^{31}$

Ang unang grupong tumutukoy sa katamaran ay may mga gawi tulad ng "ningas-kugon, bahala na, sakop mentality, at mañana." 32 Ang ningas-kugon ay ang paggawa ng mabilisan ngunit mabilis din kung tumigil. Mabuti ito dahil nagiging mabilis ang paghusga ng isang tao, subalit negatibo dahil nawawala naman ang pagpapatuloy ng isang bagay. Ang bahala na naman ay tumutukoy sa pagpapaubaya sa mga maaaring mangyari sa Bathala. Nagpapakita din ito sa pagiging bukas sa iba't ibang posibilidad na maaaring mangyari. Maganda ito dahil nagpapakita ito ng malalim na pananampalataya sa Banal. Nagiging handa rin sa lahat ng maaaring mangyari, ngunit sa kabilang dako ay nagiging tamad at umaasa na lamang sa halip na paghandaan ang mga bagay-bagay. Ang sakop na kaisapan ay tumutukoy sa pagiging kabilang ng pamilya o kasamahan sa lahat ng pagpili. Mabuti sapagkat ipinapakita nito ang pagkakaisa at samahan ng pamilya, subalit masama rin dahil halos nakasalalay na lamang ang nais ng isang tao sa nais o pulso ng nakararami. Ang mañana naman ay tumutukoy sa palagiang pagpapaliban ng mga gagawin. Maganda ito dahil ipinapakita nito ang kahinahunan at kawalan ng problema, subalit hindi rin maganda dahil sa palagiang pagkabalam ng mga takdang gawain ay wala ring natatapos. Sa puntong ito ay walang isang paliwanag ang katamaran sa mga Pilipino kundi nakasalalay lamang sa kung anong pamantayan ang gagamitin. ${ }^{33}$

Sa ikalawang grupo, kabilang naman sa pagkamakasarili ang "hiya, at kanya-kanya." 34 Ang hiya sa aspetong ito ay tumutukoy sa kawalan ng lakas ng loob na subukan ang mga ibang bagay. Kaugnay din ng konseptong ito ang dangal, kung saan dapat ay "magkaroon ng kahihiyan" o "panatilihin ang dangal." Maganda ang unang kahulugan ng hiya dahil hindi na nahihirapan at nahahadlangan ng mga bagay-bagay ang isang tao, subalit hindi rin maganda dahil hindi na nailalabas ang sariling kagalingan. Samantala, ang pag-uugnay sa hiya at dangal ay nagbubunga ng laging mabuting hangganan. Ang pagkakanya-kanya naman ay tumutukoy sa pagtatampok sa mga kabilang sa pangkat o sakop. Kaakibat din nito ang pagsasawalang bahala sa mga taong hindi kabilang sa isang grupo. Mabuti ito dahil natututo ang bawat isa na pahalagahan ang pamilya o ang samahan, subalit masama dahil nagiging limitado ang pakikisama sa pamilya o sa iilang grupo lamang. ${ }^{35}$

${ }^{31}$ Emerita S. Quito, “The Ambivalence of Filipino Traits and Values," in Karunungan: A Journal of Philosophy 5 (1988), 42-45.

${ }^{32} \mathrm{Ibid}$.

${ }^{33}$ Ibid.

${ }^{34}$ Ibid.

${ }^{35} \mathrm{Ibid}$.

(c) 2017 Rodrigo D. Abenes and Jerwin M. Mahaguay https://www.kritike.org/journal/issue 21/abenes\&mahaguay december2017.pdf ISSN 1908-7330

(c) BY-NC-ND 
Sa ikatlong grupo ay binigyang-pansin ni Quito ang kahinahunan ng mga Pilipino, Ito ay makikita sa mga gawi tulad ng "pwede na at ok lang." 36 Ang pwede $n a$ ay nagpapakita ng pagtanggap sa mga bagay-bagay anuman ang kayarian nito. Ito ay mabuti dahil walang nasasaktan at natatapakan sa ganitong patakaran. Gayon din ang ok lang; malinaw ang pagpayag at pagsang-ayon kahit walang pag-aaral na ginawa, ang mahalaga ay mapagbigyan at hindi makasakit ng iba. Subalit sa puntong ito, tila pinipilit na lamang tanggapin ng mga Pilipino ang isang bagay kahit hindi siya nasisiyahan o sumasang-ayon sa dahilang gusto niyang masiyahan ang isang tao at ayaw makasakit ng damdamin ng iba. Sa gayon ay nasasakripisyo ang kalidad o kagalingan ng mga gawain.

Ang huling grupo ay may kinalaman sa kaduwagan ng mga Pilipino sa pagtanggap sa sariling pagkakamali. Ayon kay Quito, ang mga salitang tulad ng "saving face, akala ko, at kasi" 37 ay sumasalamin dito. Ang akala ko ay ang dagliang paghuhugas kamay sa isang pangyayari, samantalang, ang kasi ay tumutukoy sa pagbibigay ng dahilan kung bakit nangyari o nagawa ang isang bagay. Mabuti ang mga ito sapagkat nagpapakita ito ng bilis ng isip at kakayahang linisin ang pangalan sa mga 'di magandang nagaganap. Subalit hindi rin ito maganda sapagkat nagpapahiwatig ang akala ko ng kakulangan ng mga Pilipino sa kritikal na pag-iisip, hindi muna pagsisiyasat o pagtatanong bago gumawa ng isang bagay kaya malimit ay walang kaayusan. Bukod ditto, ang kasi ay nagpapakita ng pagtalikod sa negatibong ginawa, gusto lagi ay may masisisi.

Mapapansing may kaguluhan ang direksyon ng mga gawing ito. Ito ay sa kadahilanang ang kagawiang Pilipino ay bunga ng pinagsama-samang: "relihiyon ng mga Kastila, teknolohiya ng mga Amerikano, at diwa ng mga Asyatiko." ${ }^{38}$ Sa gayon ay naghahalo-halo at hindi maintindihan kung ano at saang pagkakataon mas makatutulong at kapaki-pakinabang ang isang kagawian. Kaya nga malinaw na sinabi ni Quito na "ang magaling na pilosopiya ng edukasyon para sa mga Pilipino ay maglalagay ng kaayusan sa ating mga katangiang negatibo." 39

\section{Pagpapahalaga}

"Ang pagpapahalaga ang batayan ng katarungan"40 para kay Quito. Ang katarungan ay ang pagbibigay kung ano ang nararapat kaninuman, sinuman, at saanman. Malawak itong usapin dahil sa bawat sitwasyon ay

\footnotetext{
${ }^{36}$ Quito, "Pilosopiya ng Edukasyon sa Diwang Filipino," 4.

${ }^{37} \mathrm{Ibid}$.

${ }^{38}$ Quito, “Ang Pilosopiya: Batayan ng Pambansang Kultura," 686.

${ }^{39}$ Quito, "Pilosopiya ng Edukasyon sa Diwang Filipino," 5.

${ }^{40}$ Ibid.
}

(C) 2017 Rodrigo D. Abenes and Jerwin M. Mahaguay https://www.kritike.org/journal/issue 21/abenes\&mahaguay december2017.pdf ISSN 1908-7330 
maaaring magkaroon ng napakaraming batayan kung paano ibibigay ang mas malaki o mas maliit sa isang pangkat. Kaya naman, mahalagang linawin ang pamantayan ng pagpapahalaga. Sa pag-aaral ni Quito sa mga Pilipino ay naghanay siya ng mga batayan ng pagpapahalaga para sa mga Pilipino. Ilan sa mga batayang ito, ayon kay Quito, ay ang mga sumusunod: "utang na loob, hiya, amor propio, pakikisama, at pagmamahal sa pamilya." 41

Ang utang na loob ay tumutukoy sa pagkilala sa sinumang tumulong o nagbigay pabor sa kanila. Sa gayon, kung sakaling dumating ang panahong sila naman ang humingi ng tulong ay hindi niya ito maaaring tanggihan dahil sa kanyang pagkakautang. Mabuti ang pagkilalang ito sapagkat naroon ang elemento ng seryosong pagkilala at pagpapasalamat, subalit nagiging negatibo ito dahil, una, may mga seryosong pabor na hindi dapat basta-basta ibinibigay subalit kapag nahilingan ng pinagkaka-utangang loob ay napipilitang ibigay (tulad na lamang ng boto sa mga politiko). Sa gayon ay nasasakripisyo ang katotohanan, ang kalidad, at ang pag-unlad sa pangkalahatan.

Malaki rin ang pagpapahalaga ng mga Pilipino sa mga pangalan, pamilya, at trabaho. Sinumang nagtataglay ng mga ito ay masasabing kinikilala sa lipunan. Sa puntong ito makikita na kalimitan ay lagi silang napapaburan at hindi naitatama ang kanilang mga mali dahil sa hiya sa kanila. Sa gayon ay naaabuso ang mga batas at tungkulin para lamang hindi mapahiya ang ibang tao. Halos katulad na rin nito ang pakikisama. Lahat ay gustong maging masaya, kaya lahat, kung maaari, ay pakikisamahan at bibigyan ng pabor.

Sa huli ay namamayani ang pamilya sa lahat ng bagay. Kaya lumilitaw ang mga kasabihang "mas matimbang ang dugo kaysa sa tubig." Sa lahat ng pagkakataon ay makikitang hindi maaaring iwan o ipagpalit ang pamilya. Kaya naman, sa sobrang pagmamahal sa pamilya, kasama pa rin sila kahit na may asawa na ang isang miyembro nito. Dito masasalamin ang hilaw na pagpapahalaga ng mga Pilipino sapagkat imbes na bayan bago ang sarili ay mas nauunang bigyan ng prioridad ng mga Pilipino ang sariling pangarap kaysa sa kagalingang pambayan at pambansa.

\section{Pagbalik sa Diwang Pilipino sa pamamagitan ng Dekolonisasyon}

\section{Dekolonisasyon at Edukasyon}

Edukasyon ang sinandalan ni Quito upang maibalik ang diwang Pilipinong niyurakan ng mga dayuhan. Malinaw kay Quito na hamon sa mga

${ }^{41}$ Ibid.

(c) 2017 Rodrigo D. Abenes and Jerwin M. Mahaguay https://www.kritike.org/journal/issue 21/abenes\&mahaguay december2017.pdf ISSN 1908-7330

(c) BY-NC-ND 
Pilipino na "we must reformulate our educational goals towards nationalist-oriented ideals." 42 Mapapansing isinusulong ni Quito ang paglalagay sa nasyonalismo bilang "a consciously directed policy"43 sa lahat ng larangan sa bansa. Sa ganitong punto, hindi lamang paglalagay o pagpapayabong ng kaalaman tungo sa kaunlaran, paglalatag ng tamang gawi at pagpapahalaga, pagbuo ng kritikal na pag-iisip, ang mga layunin ng edukasyon para sa mga Pilipino; kundi, ito rin ay maglalagay ng nasyonalismo sa mga mamamayan bilang pundasyon ng lahat ng pagkatuto. Ang nasyonalismo ang magbubuklod sa lahat ng pagkakaibang dinadala dulot ng relihiyon, wika, lugar, at pamilya.

Bagama't buo ang paniniwala ni Quito na edukasyon lamang ang makapagpapanumbalik sa diwang Pilipino, kakaibang edukasyon ang nais niya at may paghamon nga niyang sinabing "kung nais natin ang edukasyon na tunay na maka-Pilipino, nararapat magkaroon ng 'Filipinization' sa lahat ng larangan." 44 Ang 'Filipinization' ay ang pagsasabuhay o pagpapanumbalik ng mga kalinangan, gawi, at pagpapahalaga ng mga Pilipino. Ayon kay Quito "ang Pilipinas ay may kalinangan bago pa man dumating ang mga Kastila, kalinangan na matatawag na Pilipino." 45

Maisasakatuparan ang 'Filipinization' sa pamamagitan ng "dekolonisasyon o pagkalas sa kalinangan ng mga kongkistador." 46 Ang pagkalas na ito ay marahas dahil "bubungkalin nito ang nasa pinakamalalim sa kaluluwa ng taong sinakop." ${ }^{47}$ Ang karahasang ito ay walang pagpili sapagkat, ayon kay Quito, "kahit na gaano kalaki ang ambag ng mga dayuhan sa bayan gaya ng wika, relihiyon, at salapi, nararapat na ito'y ipagwalang-bahala." 48 Ito ay tumutukoy sa pangkalahatang pagtalikod na maaari ring "walang katapusan." 49 Alam ni Quito na "mahirap itong gawin, dahil mistulang pagwawalay ito ng batang munti sa kanyang ina at kapag hindi nagtagumpay ang pagwawalay na ito sa inang kultura, ang isang bayan ay mananatiling nakabilanggo sa kanyang sariling bakuran." 50 Sa gayon ay hindi ito maaaring ipagwalang-bahala sapagkat mababaliwala ang mga pinaghirapan ng mga naunang makabayang Pilipinong nagbuwis ng buhay para sa kalayaan. Matuwid na sinabi ni Quito na “ang kasarinlang

42 Emerita Quito, "Philosophy of Education for the Filipinos," in A Life of Philosophy: Festschrift in Honor of Emerita S. Quito (Manila: De La Salle University, 1990), 762.

${ }^{43}$ Ibid.

${ }^{44}$ Quito, “Pilosopiya ng Edukasyon sa Diwang Filipino," 2.

${ }^{45}$ Ibid.

${ }^{46}$ Ibid., 3.

${ }^{47} \mathrm{Ibid}$.

${ }^{48}$ Ibid.

${ }^{49} \mathrm{Ibid}$.

${ }^{50}$ Ibid., 2.

(C) 2017 Rodrigo D. Abenes and Jerwin M. Mahaguay https://www.kritike.org/journal/issue 21/abenes\&mahaguay december2017.pdf ISSN 1908-7330 
ipinagkaloob lamang ay walang kabuluhan kung ang mga taong sinakop ay patuloy pang tumatangkilik sa landas ng buhay ng kongkistador." 51

Sino naman ang gaganap sa tungkuling ito? Para kay Quito, "malaki ang pananagutan ng mga katutubong-intelektuwal sapagkat sa kanila nakasalalay ang pagbangon ng isang sariling kalinangan o kultura." Dagdag pa niya "tungkulin ng mga intelektuwal ang kumalas sa kalinangan ng kongkistador sa pamamagitan ng pagbalangkas ng sariling kalinangan." 52 Wika ni Quito, dapat tandaan ng mga intelektuwal na "to fight for national culture means in the first place to fight for the liberation of the nation." 53

Isa sa mga na pinuri ni Quito ay si Renato Constantino, bilang isa sa mga intelektuwal na nag-umpisa ng ganitong gawain. Bahagi ng dekolonisasyon ang muling pagsulat ng kasaysayan hango sa pananaw ng mga Pilipino at hindi sa pananaw ng mga Kastila. Hindi na dapat sabihing natuklasan ang Pilipinas noong 1521 sapagkat naroon na ang Pilipinas bago pa man dumating ang mga Kastila at mayroon nang kalinangang matatawag na Pilipino. Nararapat na bigyang dangal din hindi lamang si Rizal kundi maging sina Lapu-lapu at iba pang bayani. Mahalaga ring ipagpatuloy ang pagsulat ng kasaysayan sa pananaw Pilipino tulad ng pagkilala kina Benigno Aquino bilang mga bagong bayani. ${ }^{54}$

\section{Dekolonisasyon at Wika}

Ang unang hakbang patungo sa dekolonisasyon, ayon kay Quito, ay ang pagtataguyod ng sariling wika upang mas mapalakas ang pambansang damdamin at kamalayan. Ang kanyang diskurso ay hindi nalalayo sa hakbangin nina Zeus Salazar ${ }^{55}$ at Prospero Covar ${ }^{56}$ ng Unibersidad ng Pilipinas. "Sa pamamagitan ng wika, tayo ay magbabalik sa mga ugat, sa pinakamalalim na adhikaing namamayani sa ating bansa." ${ }^{57}$ Makikitang ganito rin ang punto ni Salazar sa sinabi niyang "dala ng wika ang ating kulturang kanya ring pinauunlad."58 Kaya naman masasabing ang manipestasyon ng nasyonalismo ang paggamit ng wika, sapagkat para kay Quito, ang tunay na antas ng nasyonalismo ng isang tao ay nasusukat sa kung marunong siyang magsalita ng wika ng kanyang bansa. Dagdag pa niya, ang

51 Ibid., 3.

52 Ibid., 2.

${ }^{53}$ Quito, "Philosophy of Education for the Filipinos," 763.

${ }^{54}$ Quito, "Pilosopiya ng Edukasyon sa Diwang Filipino," 3.

55 Zeus Salazar. Ang Kasaysayan: Diwa at Lawak (Quezon City, Philippines: University of the Philippines Press, 1974), ix Press, Inc., 1998).

${ }^{56}$ Prospero Covar, Larangan: Seminal Essays on Philippine Culture (Manila: Sampaguita

${ }^{57}$ Emerita S. Quito, “Wikang Pambansa at Edukasyon,” in Malay 6:2 (1987), 147.

${ }^{58}$ Salazar, Ang Kasaysayan: Diwa at Lawak, x.

(C) 2017 Rodrigo D. Abenes and Jerwin M. Mahaguay https://www.kritike.org/journal/issue 21/abenes\&mahaguay december2017.pdf ISSN 1908-7330

(c) BY-NC-ND 
mga ganitong bagay ay hindi na dapat pagtalunan pa sapagkat, sinumang "nagsasaad na ang nasyonalismo at ang wika ay magkaakbay ay nakayapak sa terra firma ng magandang asal at matinong pag-iisip."

Kaya naman, hindi kataka-taka na isa sa adhikain ni Quito ay gamitin ang wikang pambansa ng mga Pilipino bilang unang wika ng bansa sapagkat "maibubunyag lamang ang malalim na kalungkutan (damdamin) o pighati kung hindi sa sariling wika." 60 Higit pa, masasabing "ang ating diwa ay mabibigyan ng wastong pag-iral sapagkat magkaugma ang diwa at wika." 61

\section{Ang Landas ng Pagtatanong sa Diwang Pilipino}

\section{Ang Posibilidad ng Diwang Pilipino}

Malinaw kay Quito na hindi makikita ang diwang Pilipino sa katangiang-pisikal ng mga Pilipino. Upang ulitin, ayon kay Quito, “kung ang hinahanap natin ay ang hugis ng katawan o kulay ng balat o tabas ng mata, ay walang kasarilinang Pilipino. Datapwat mayroong kasarilinang diwa (soul identity) ang Pilipino at hango ito sa pilosopiyang taglay ng bayang Pilipino." 62 At ang diwang ito ay makikita sa mga panitikan tulad ng tula, kwento, at kanta ng mga Pilipino. ${ }^{63}$ Lumalabas din na kahit may iba't ibang linggwahe ang mga Pilipino ay may pagkakaisa naman ang kanilang diwa dahil may pagkakatulad ang kanilang pananaw sa mundo.

Subalit ang problema sa sagot na ito ay nakatago sa nakaraan. Ang diwang ito ay kailangang balikan. Samakatuwid, binubuksan ng sagot na ito ang ilang mga mabibigat na katanungan. Una, hanggang kailan ang punto na dapat balikan para matawag na ang estadong iyon ay sa mga Pilipino? Ikalawa, kung mayroon mang Pilipino, hindi ba kasama sa kanyang pagkaPilipino ang karanasan nila sa panahon ng pananakop hanggang sa kasalukuyan? Ikatlo, posible bang maging puro ang pagiging Pilipino sa panahon ng globalisasyon?

Sa unang katanungan, hinggil sa panahon o punto kung saan may diwang matatawag na talagang Pilipino, makikitang bago pa man dumating ang mga dayuhan, ang Pilipinas ay magkahati-hati sa mga isla at linggwahe. Samakatuwid, iba-iba rin ang kanilang sining at literatura, at bunga nito ay iba-iba rin ang kanilang diwa. Kung gayon, ang diwa ng mga panahong iyon ay hindi matatawag na diwa ng isang bansa kundi diwa ng mga lahi ng bawat lugar. Maaaring ang diwang tinatawag ni Quito ay isang pangarap lamang

\footnotetext{
${ }^{59}$ Quito, "Wikang Pambansa at Edukasyon," 146.

${ }^{60} \mathrm{Ibid} ., 138$.

${ }^{61}$ Quito, “Ang Pilosopiya: Batayan ng Pambansang Kultura," 688.

${ }^{62}$ Quito, “Ang Pilosopiya: Batayan ng Pambansang Kultura," 686.

${ }^{63} \mathrm{Ibid}$.
}

(C) 2017 Rodrigo D. Abenes and Jerwin M. Mahaguay https://www.kritike.org/journal/issue 21/abenes\&mahaguay december2017.pdf ISSN 1908-7330 


\section{DEKOLONISASYON AT DIWANG PILIPINO}

bago pa man dumating ang mga dayuhan, at ang nagpatibay lamang ng pagiging isang bansa ay ang pangkalahatang pagdanas ng karahasan dulot ng mga Kastila. Ngunit sa ganitong paraan, tila wala namang isang diwa ang mga Pilipino, bagkus, nagkaroon lamang ng isang pangkalahatang pagkilos dahil ang lahat ay nakaranas ng karahasang nagbunsod ng isang pareparehong kasagutan. Dito makikitang hindi diwa ang naging dahilan ng pangkalahatang pagkilos kundi ang sama-samang pagdanas ng isang bagay sa ilalim ng mga dayuhan.

Sa ikalawang katanungan, kung sakali man at mayroon ngang diwang Pilipino bago pa man dumating ang mga dayuhan, at ang diwang ito ay nasakop ng mga Kastila, maaari bang sabihing ang karanasan sa panahon ng pananakop ay bahagi na rin ng pagka-Pilipino? Sa puntong ito ay magandang tingnan ang diwa o ang sarili na hindi binubuo ng isang esensyang sa simula't simula pa lamang ay buo na; sa halip, ang diwa o ang kasarinlan ng bansa ay nagpapatuloy at binubuo. Tulad ng isang tao, ang kanyang mga karanasan, mabuti man ito o masama, ay bahagi na ng kanyang pagkatao. Ganito rin ang mas mainam na pagtingin sa bansa. Ang mga natutunan sa panahon ng pananakop ay hindi na maaaring alisin bilang aspeto ng pagka-Pilipino.

Ang huli naman ay tumutukoy sa pagka-Pilipino sa panahong kasalukuyan. Ang daigdig ay umiikot sa ilalim ng globalisasyon kung saan bawat bansa ay nakaaapekto sa isa't isa. Ang mga gawi, pagpapahalaga, at kalinangan ng isang bansa ay mabilis nang nakararating sa iba. May kasarinlan pa bang matatawag ang isang Pilipino kung saan ang pagkaPilipino ay ngayo'y itinatakda sa bisa ng batas? Ayon sa Saligang Batas ng Pilipinas 1987 ang mga Pilipino ay ang mga sumusunod:

[1] Those who are citizens of the Philippines at the time of the adoption of this Constitution;

[2] Those whose fathers or mothers are citizens of the Philippines;

[3] Those born before January 17, 1973, of Filipino mothers, who elect Philippine citizenship upon reaching the age of majority; and

[4] Those who are naturalized in accordance with law ${ }^{64}$

Napakapayak ng pagka-Pilipino kung susundan ang lohika ng mga pamantayan na nasa itaas. Makikita nga rin dito na hindi naman mahalaga kung gumagamit ka ng wikang Pilipino o hindi. Hindi kailangang alam mo ang pagpapahalaga o gawi ng nakararami. Ang mahalaga ay kinikilala ka ng

${ }^{64}$ The 1987 Constitution of the Republic of the Philippines, Art. 4, §1-4.

(c) 2017 Rodrigo D. Abenes and Jerwin M. Mahaguay https://www.kritike.org/journal/issue 21/abenes\&mahaguay december2017.pdf ISSN 1908-7330

(c) BY-NC-ND 
batas bilang isang Pilipino. Kung kaya't kahit sa ibang bansa isinilang ang isang tao, at doon na nanirahan, at kalauna'y babad na sa kalinangang dayuhan, masasabing Pilipino pa rin siya kung siya'y anak ng isang Pilipino, kahit wala siyang nalalaman patungkol sa kulutura nito. ${ }^{65}$

\section{Globalisasyon at ang Posibilidad ng Dekolonisasyon at Filipinisasyon}

Maaari ba talagang magkaroon ng dekolonisasyon? Magandang pagnilayan sa puntong ito-bilang paraan na rin ng pagbatikos sa problema ng dekolonisasyon sa panahon ng globalisasyon na siyang pinagtuunan ng pansin ni Quito - ang dalawang pagtingin sa globalisasyon: una, tumutukoy ito sa paglalapit-lapit ng lugar at pagpapablis ng oras na siyang may malinaw na epekto sa kalinangang Pilipino; ikalawa, ang pagtukoy sa globalisasyon bilang ideolohiyang nakatuon sa prinsipyo ng malayang pamilihan na tuwirang nanghihimasok sa kamalayang Pilipino. ${ }^{66}$

Sa unang pag-unawa sa globalisasyon, masasabing napakabilis nang makarating ng mga dayuhan sa Pilipinas at gayundin ang mga Pilipino sa ibang bansa. Sa ganitong punto, napakabilis na ng palitan ng mga kalinangan at teknolohiya. Ang ganitong sitwasyon ay hindi maaaring iwasan lalo na sa isang sistema ng pamahalaang demokratiko. Mas pinapalala pa nito ang malawakang kultura ng migrasyon. Ang mga Pilipino ay pumupunta sa ibang bansa upang magtrabaho at manirahan, samantalang ang iba naman ay bumabalik dala ang kalinangang dayuhan. Gayundin ay palasak ang mga dayuhang naninirahan sa bansa upang magnegosyo o mag-aral kaya naman tiyak na ang palitan ng kalinangan ay hindi maiiwasan.

Sa ikalawang bahagi naman, ang ideolohiya ng globalisasyon ay makikita sa pagkalat ng mga multinational-supranational na korporasyon kung saan ang epekto sa mga tao, sa kanilang trabaho at pamumuhay, ay kakaiba. Ang mga ito ay nasa media, pamahalaan, pamilihan, at paaralan. Kaya tiyak na ang pagbalik ay isang napakalayong gawain. Kasabay din nito ang walang hanggang bukal ng impormasyon o kaalaman. Hindi kayang harangan ang pagpasok ng mga mamamayan sa cyber world, virtual reality, o internet. Hindi na lamang paaralan ang lugar kung saan pwedeng matutuo ang mga bata patungkol sa ibang kamalayan. Bukas na rin ang pagkakataong ito sa pamamagitan ng internet, kung saan ay wala nang sakop ang gobyerno. Maaari rin naman ngang magkaroon ng mga batas upang ito ay limitahan, subalit hindi ito kaaya-aya sa isang demokratikong bansa.

\footnotetext{
${ }^{65}$ Mahaguay, Ang Pilosopiya ng Edukasyon para sa mga Pilipino ayon kay Emerita S. Quito: Isang Pagsusuri.

${ }^{66} \mathrm{Ibid}$.
}

(C) 2017 Rodrigo D. Abenes and Jerwin M. Mahaguay https://www.kritike.org/journal/issue 21/abenes\&mahaguay december2017.pdf ISSN 1908-7330 


\section{DEKOLONISASYON AT DIWANG PILIPINO}

Samantalang kung talagang mangyayari man na maipatupad ang dekolonisasyon, hanggang saan kaya masasabing naabot na ang kalinangang Pilipino? Malinaw kay Quito na bago pa man dumating ang mga dayuhan ay mayroon ng kalinangan na matatawag na Pilipino. Subalit Pilipino na nga ba sila dati? May mga pananaw nagsasabing hindi naman talaga sila Pilipino, o gumagalaw bilang isang bansa. Kumikilos sila batay sa angkan o lugar kaya ang himagsikan ay pangprobinsya lamang at hindi kilos ng isang bansa. Kung gayon, kaninong kalinangan ang marapat na balikan: sa mga Ilokano, Bisaya, Tagalog, o Muslim?

Samantalang kung babalikan ang salitang Filipino ay masasabing hindi naman talaga ito tumutukoy sa mga Pilipino (sa diwa na iniisip natin bilang mga taga-Pilipinas bago pa man dumating ang mga Kastila). Ang Pilipino ay tumutukoy sa mga purong mga Espanyol na ipinanganak sa Pilipinas o mas kilala sa tawag na 'insulares.' Kung magkagayon, ang dekolonisasyon ay paghahawan pa rin o pag-aalis ng pagka-Pilipino ng mga Pilipino, upang lumitaw ang tunay na kalinangan ng mga tao bago dumating ang mga Kastila. Ito ang tinatawag nating pagkakasakatutubo.

\section{Filipinisasyon}

Sa ganitong punto, makikitang ang Filipinisasyon ay pagsasakatutubo. Pero sino nga ba ang mga katutubo? Sila ba ay iyong mga Igorot, Ilokano, o Muslim? Ang mga grupo ng taong ito ay mayroong iba't ibang kultura at wika. Subalit noo'y hindi rin nila alam na sila ay isang bansa. Marami ngang mga tala na ang bawat isa ay may alitan. Kung ganito man, ang Filipinasasyong pagsasa-katutubo ay pagbalik lamang sa panahon ng pagkawawatak-watak o pagkakanya-kanya. Ito ay tuluyan lamang sasalungat sa layunin ni Quito na pagkabubuklod-buklod.

Sa isang banda, subukan nating bigyan ng puwang ng pagdududa, na noon pa man ay mayroon na noong diwang-katutubo na sinasabi ni Quito. Masasalamin ito sa pagkakatulad ng mga panitikan ng magkakaibang kulturang (Ilokano, Tagalog, Bisaya, Muslim). Ang mga susunod na katanungan naman ay: kung magtagumpay man ang dekolonisasyon at mailagay ang antas ng kalinangan, pagpapahalaga, at gawi ng isang Pilipino (katutubo), papaano ito isasabuhay? Posible ba ang isang kalinangang walang bahid ng ibang kultura sa panahong kasalukuyan? Magandang tingnan ang paksang ito sa apat na aspeto: kahalagahan, paraan, responsibilidad, wika at pag-unlad. ${ }^{67}$

Patungkol sa kahalagahan, maaaring itanong kung mayroon bang kalinangan, gawi, at pagpapahalaga ang mga Pilipino bago pa man dumating

${ }^{67} \mathrm{Ibid}$.

(c) 2017 Rodrigo D. Abenes and Jerwin M. Mahaguay https://www.kritike.org/journal/issue 21/abenes\&mahaguay december2017.pdf ISSN 1908-7330

(c) BY-NC-ND 
ang mga dayuhan. Maaari pa ba itong balikan para masabing mahalaga pa ito at kapaki-pakinabang sa panahong kasalukuyan? Halimbawa na lamang ay ang paraan ng pagsulat. Kung sakaling ituturo ang 'Baybayin' sa mga kabataan sa kasalukuyan, mahalagang tingnan kung ito ay mas magdudulot ng kaunlaran sa mamamayan o lalo lamang magiging magulo at lalayo sa makabagong panahon ang mga Pilipino. Hindi kaya mas lalo lamang maiwan ang mga Pilipino sa paraan ng pagbalik na ito? Isa pang halimbawa ay ang pagtaas ng mga Tagalog kay Bathala sa paggamit ng "bahala na." Mas makatutulong ba ito sa buhay Pilipino? May mga pagkakaiba ba ito sa pananampalatayang Kristiyano Katoliko, o baka naman binabago lamang ang salita pero ang gawa at ang diwa ay ganoon pa rin? Hindi ba dapat ang pagpapahalaga at gawi ay tutugon upang makasabay ang tao sa kasalukuyang takbo ng buhay at hindi dapat ang kasalukuyan ang makikibagay sa gawi at pagpapahalaga ng mga tao?

Mahalagang saysayin ang kahalagahan ng diyalogo ng tao at kalagayan sa kaligiran ng pag-unlad at edukasyon. "Without dialogue there is no communication, and without communication there can be no true education."68 At sa diyalogo ay hindi maaaring isa lamang ang magdidikta, marahil ay may kalinangang babalikan at may mga iiwanan na rin kung ito ay hindi na mahalaga o kailangan. Samakatuwid, ang Filipinisasyon o pagsasakakatutubo, ay dapat pagpili lamang ng mga kalinangang makatutulong sa atin. Marapat lamang ang paglimot sa mga hindi na kailangan.

Ikalawa, ang pamamaraang hangad ni Quito ay nagsisimula sa mga intelektuwal o dalubhasa at pagkatapos ay tumutuloy sa pagsuporta sa pamahalaan at sa lahat ng aspeto ng lipunan. Dito makikita ang kapangyarihan na ibinibigay ni Quito sa paaralan na tila hindi na isang katotohanan sa paraang kasalukuyan. Talas naman ni Quito ang kakayahan ng mga korporasyon pero hindi niya nakitang maaari ring pasukin ng korporasyon ang sagradong lugar ng pamantasan. Sapagkat sa kasalukuyan ay nagiging isang korporasyon na rin ang mga paaralan. Hindi na kultura at bayan ang pangunahing layunin nito, kundi ang mga tubo o kita bilang korporasyon ang patakaran. Ang mga intelektuwal ay unti-unting naglalaho sa pagharap sa kanilang responsibilidad para sa ikauunlad ng karunungan. Bagkus, sila'y nagiging sunud-sunuran na lamang para sa ikauunlad ng pamantasan. Kung magkagayon, ang kapangyarihan ay wala na sa mga dalubhasa kundi nasa administrador na ng pamantasan, o dili kaya ay sa mga may-ari ng nito. Ang isa pang punto ay nawawalan na ng kapangyarihan ang pamantasan sa pagtatanghal ng antas ng kaalaman, lumalakas na rin ang antas ng mga pribadong korporasyon sa larangan ng pananaliksik. Ayon nga

${ }^{68}$ Paulo Freire, Pedagogy of the Oppressed, trans. Maya Bergman Ramos (New York: Continuum, 2005), 92-93.

(C) 2017 Rodrigo D. Abenes and Jerwin M. Mahaguay https://www.kritike.org/journal/issue 21/abenes\&mahaguay december2017.pdf ISSN 1908-7330 


\section{DEKOLONISASYON AT DIWANG PILIPINO}

sa ilang pananaw, minsan ay mas mataas pa ang antas ng sertipiko na iginagawad ng isang korporasyon, halimbawa ay Microsoft, kaysa sa isang pamantasan. Sa puntong ito ay napakamasalimuot ang pagbalik at pagsasakatuparan ng Filipinisasyon.

Ang panghuling aspeto ay ang usapin tungkol sa wika. Maganda ang panukala ni Quito na gumamit ng isang wikang matatawag na Filipino. Kahit anong diyalekto man ito, ang mahalaga ay ang pagkakasundong gagamitin ito para sa ikauunawa at pagkakaisa ng lahat. Subalit hindi lamang usapin ng nasyonalismo ang isinasaalang alang sa kasalukuyang diskurso. Kasama na rin dito ang nasyonaslismo, edukasyon, ekonomiya, at globalisasyon sa pangkalahatan.

$$
\begin{array}{r}
\text { College of Graduate Studies and Teacher Education Research } \\
\text { Philippine Normal University, Manila, Philippines } \\
\text { College of Education } \\
\text { University of Rizal System - Pililla, Rizal, Philippines }
\end{array}
$$

\section{References}

Abulad, Romualdo E., Introduction to Emerita S. Quito, A Life of Philosophy: Festschrift in Honor of Emerita S. Quito (Manila: De La Salle University Press, 1990).

Covar, Prospero, Larangan: Seminal Essays on Philippine Culture (Manila: Sampaguita Press, Inc., 1998).

De Leon, Emmanuel C. "Emerita S. Quito (1929-): Ang Ugat ng Isang Panibagong Direksiyon ng Pamimilosopiya sa Pilipinas," in Malay 29:2 (2017).

Demeterio, F.P.A. III, "Status and Directions for 'Filipino Philosophy' in Zialcita, Timbreza, Quito, Abulad, Mabaquiao, Gripaldo, and Co," in

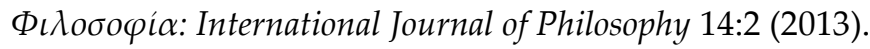

"Thomism and Filipino Philosophy in the Novels of Rizal: Rethinking the Trajectory of Filipino Thomism," in Academia, < https://www.academia.edu/7340247/Thomism and Filipino Philos ophy in the Novels of Jose Rizal Rethinking the Trajectory of Filipino Thomism>.

Enriquez, Virgilio, From Colonial to Liberation Psychology: The Philippine Experience. (Manila, Philippines: De La Salle University Press, 1994).

Fernandez, Pablo, History of the Church in the Philippines (1521-1898) (Manila: National Book Store, 1979).

Freire, Paulo, Pedagogy of the Oppressed, trans. by Maya Bergman Ramos (New York: Continuum, 2005) 
Mahaguay, Jerwin M., Ang Pilosopiya ng Edukasyon para sa mga Pilipino ayon kay Emerita S. Quito: Isang Pagsusuri (Ph.D. Dissertation, Manila, Philippines: De La Salle University, 2013).

"Nasyonalismo: Lakas ng Edukasyong Pilipino," in Kaisipan: Ang Opisyal na Dyornal ng Isabuhay, Saliksikin, Ibigin ang Pilosopiya (ISIP) 1:1 (2013).

Quito, Emerita S., "A Filipino Volksgeist in Vernacular Literature," in A Life of Philosophy: Festschrift in Honor of Emerita S. Quito (Manila: De La Salle University, 1990).

"Ang Pilosopiya: Batayan ng Pambansang Kultura," in A Life of Philosophy: Festschrift in Honor of Emerita S. Quito (Manila: De La Salle University, 1990).

"Philosophy of Education for the Filipinos," in A Life of Philosophy: Festschrift in Honor of Emerita S. Quito (Manila: De La Salle University, 1990).

"Structuralism and the Filipino Volksgeist," in A Life of Philosophy: Festschrift in Honor of Emerita S. Quito (Manila: De La Salle University Press, 1990).

"The Ambivalence of Filipino Traits and Values," in Karunungan: A Journal of Philosophy 5 (1988).

The State of Philosophy in the Philippines (Manila: De La Salle University Press, 1983).

, Wikang Pambansa at Edukasyon," in Malay 6:2 (1987).

Salazar, Zeus, Ang Kasaysayan: Diwa at Lawak (Quezon City, Philippines: University of the Philippines Press, 1974).

The 1987 Constitution of the Republic of the Philippines.

(C) 2017 Rodrigo D. Abenes and Jerwin M. Mahaguay https://www.kritike.org/journal/issue 21/abenes\&mahaguay december2017.pdf

ISSN 1908-7330 